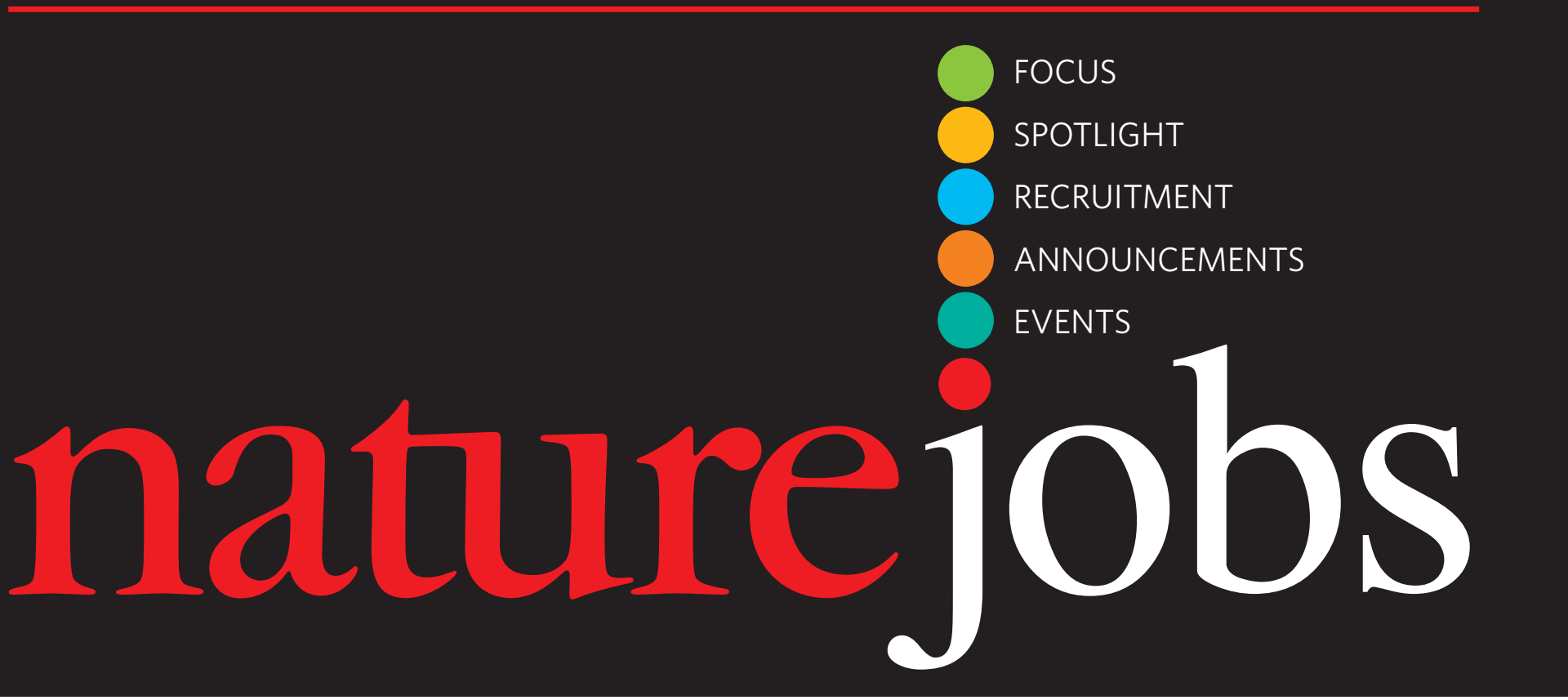

\title{
The exception to the rule
}

For postdocs at the University of Texas Southwestern Medical Center in Dallas, the old adage 'be careful what you wish for, because it might come true' seems apt. Earlier this year, a survey by its postdoc association found that $84 \%$ of the centre's postdocs supported the idea of a campus-wide policy on issues such as salary.

Since then, the postdocs have been granted their wish: the campus has instituted a uniform pay policy. But the stipend levels are below the recommended minima set by the US National Institutes of Health (NIH), and well below salaries offered by industry or private research foundations.

Despite this, there is much good to say about both the concept and the process. Postdoc pay at many institutions varies - sometimes widely — from department to department, and even between people with similar training and experience. At Texas, the medical centre worked with postdoc representatives from each of its 13 departments to set more uniform pay standards, and succeeded in levelling the playing field.

But just how level should that playing field be? Although the idea of pay parity seems sensible, there is some movement away from it, at least in special cases. Some organizations are offering what I call 'super postdocs'. These fellowships have much higher salaries and responsibilities and can serve as a much-needed bridge between a postdoc and a position as an independent investigator. Should those programmes be eliminated in the name of parity? Most sensible scientists would say no.

So how about a compromise, taking the best elements of all these approaches? Postdocs should certainly be involved in the stipend negotiation process. But rather than a ceiling, these stipend levels should represent a floor, that at least matches the lowest NIH recommended level. And they should allow exceptional compensation for exceptional cases. Such a system would be well worth wishing for.

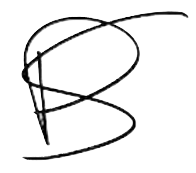

\section{Paul Smaglik, Naturejobs editor}

Natureevents: Sille Opstrup (4994) Fax: +44 (0) 2078434996 UK/RoW/Ireland/Italy:

Nils Moeller (4953)

Irene Viglia-Atton (4944)

Scandinavia/Spain/Portugal:

Evelina Rubio Håkansson (4973)

France/Switzerland/Belgium:

Amelie Pequignot (4974)

Germany/Austria/The Netherlands:

Reya Silao (4970)

Advertising Production Manager:

Billie Franklin

To send materials use London

address above.

Tel: +44 (0) 2078434814 e-mail: naturejobs@nature.com

Naturejobs web development: Tom Hancock Naturejobs online production: Niamh Shields

European Satellite Office

Germany/Austria/

The Netherlands:

Patrick Phelan

Tel: +498954905711

Fax: +498954905720

e-mail:p.phelan@nature.com

US Head Office, New York

345 Park Avenue South,

10th Floor, New York,
NY 10010-1707

Tel: +18009897718

Fax: +18009897103

e-mail: naturejobs@natureny.com

US Sales Manager: Peter Bless

Japan Head Office, Tokyo

Chiyoda Building,

2-37 Ichigayatamachi,

Shinjuku-ku,

Tokyo $162-0843$

Tel: +81332678751

Fax: +81332678746

Asia-Pacific Sales Director: Rinoko Asami

e-mail: r.asami@naturejpn.com 